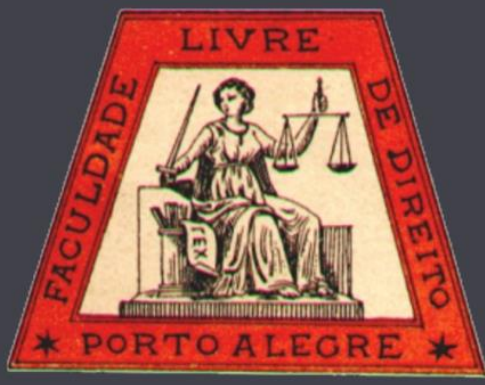

Análise das ações afirmativas relativas à educação inclusiva no ensino do autista: a necessidade de monitor em sala de aula

Analysis of the affirmative actions on the inclusive education of autists: the requirement of a monitor in the classroom

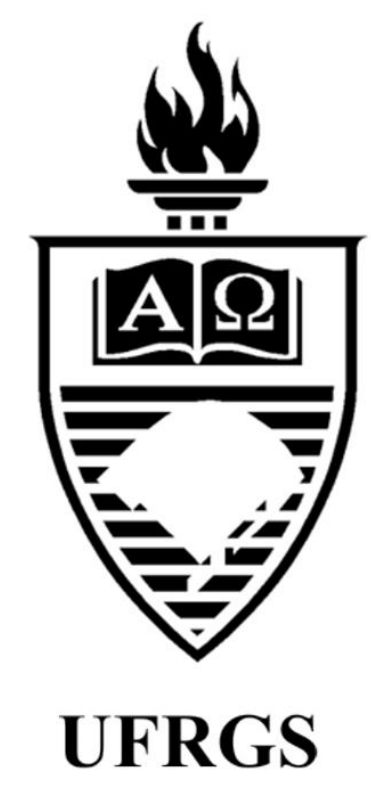

Bianca Goulart dos Santos

Universidade de Caxias do Sul

Marcelo Schenk Duque

Universidade Federal do Rio Grande do Sul

Revista da Faculdade de Direito da UFRGS

ISSN: 0104-6594 Site http://seer.ufrgs.br/revfacdir

Faculdade de Direito da UFRGS - Rua Riachuelo, 1317 - Centro - Porto Alegre - RS - Brasil

CEP - 90010-271 - Telefone: +55 5133083118 - Site http://www.ufrgs.br/direito/ 


\title{
Análise das ações afirmativas relativas à educação inclusiva no ensino do autista: a necessidade de monitor em sala de aula
}

\author{
Analysis of the affirmative actions on the inclusive education of autists: the requirement of a monitor \\ in the classroom
}

Bianca Goulart dos Santos*

Marcelo Schenk Duque**

\section{REFERÊNCIA}

SANTOS, Bianca Goulart dos; DUQUE, Marcelo Schenk. Análise das ações afirmativas relativas à educação inclusiva no ensino do autista: a necessidade de monitor em sala de aula. Revista da Faculdade de Direito da UFRGS, Porto Alegre, n. 35, p. 99-115, dez. 2016.

\begin{abstract}
RESUMO
$\mathrm{O}$ estudo dedica-se a analise constitucional dos preceitos das ações afirmativas que envolvem a educação inclusiva do autista. Dá-se ênfase à necessidade do aluno autista em ter um monitor em sala de aula e consequências jurídicas decorrentes, diante das necessidades educacionais especiais. $\mathrm{O}$ trabalho explora o aspecto multidisciplinar do conceito e das particularidades do autismo a fim de delimitar os aspectos constitucionais do tema e a atuação do operador do direito em face das ações afirmativas. A partir desses conceitos, interpreta-se a legislação infraconstitucional e sua aplicação perante as instituições de ensino público e privado. Por fim, enfrenta-se o debate perante o Supremo Tribunal Federal a respeito da educação inclusiva nas escolas privadas.
\end{abstract}

\section{PALAVRAS-CHAVE}

Direitos fundamentais. Educação inclusiva. Ações afirmativas. Hermenêutica constitucional. Autismo. Acompanhante especializado.

\section{ABSTRACT}

The aim of this work is to make a constitutional analysis of the affirmative actions precepts involving the inclusive education of autists. Emphasis is placed on the need of a person responsible for monitoring the autist inside the classroom, as well as its legal consequences. Firstly, the multidisciplinary features of the concept and the particularities of autism are explored. Based on these understandings, legal features about the subject are delimited. Using these concepts as a base, an interpretation of the infraconstitutional legislation is carried out, linked to the public and private institutions. Finally, the debate on the Supreme Federal Court is faced having as a guide the inclusive education in private schools.

\section{KEYWORDS}

Fundamental rights. Inclusive education. Affirmative actions. Constitutional hermeneutics. Autism. Classroom monitor.

\section{SUMÁRIO}

Introdução. 1. O autismo e as necessidades educacionais do aluno autista: ênfase na presença do monitor em sala de aula. 2. O direito à educação inclusiva como direito fundamental. 3. Direitos sociais diante da reserva do possível e da máxima efetividade da Constituição Federal. 4. Ações afirmativas relativas à educação inclusiva do autista. 5. A

\footnotetext{
* Especialista em Direito Público lato sensu (Universidade de Caxias do Sul - UCS, 2015, em convênio com a Escola Superior de Magistratura Federal do Rio Grande do Sul - ESMAFE-RS). Graduada em Direito (Pontifícia Universidade Católica do Rio Grande do Sul - PUCRS, 2015). Advogada.

** Professor da Especialização em Direito do Estado da Universidade Federal do Rio Grande do Sul, de Direito Público da Escola Superior da Magistratura Federal do Rio Grande do Sul - ESMAFE-RS, do Centro Universitário Ritter dos Reis UniRITTER, da Faculdade Dom Bosco de Porto Alegre, da Faculdade IDC, da Universidade Regional Integrada do Alto Uruguai e das Missões, da Escola Superior de Advocacia da OAB e do curso de especialização em Direito do Estado da Universidade Federal do Rio Grande do Sul - UFRGS. Doutor em Direito do Estado (Universidade Federal do Rio Grande do Sul - UFRGS, com período sanduíche na Ruprecht-Karls-Universität Heidelberg, Alemanha). Graduado em Direito e em Engenharia Química (Pontifícia Universidade Católica do Rio Grande do Sul - PUCRS).
} 
educação inclusiva com a presença de monitor no ensino público. 6. A educação inclusiva com a presença de monitor no ensino privado. 7. Estudo de caso: ação direta de inconstitucionalidade 5.357. Conclusão. Referências.

\section{INTRODUÇÃO}

Sobrevindo a promulgação das Leis $\mathrm{n}^{\circ}$ 12.764, de dezembro de 2012, e 13.146, de julho de 2015, que tratam do direito à educação inclusiva das pessoas com deficiência e, particularmente, do autista, o debate constitucional acerca do tema é premente. Perante o Supremo Tribunal Federal, por meio da Ação Direta de Inconstitucionalidade 5.357, se discutiu a vinculação da rede de ensino privada aos ditames do Estatuto da Pessoa com Deficiência. Nesse ínterim, o presente estudo visa o debate sobre as ações afirmativas que envolvem a educação do autista, a matéria correlata ao tema, e a vinculação dos entes públicos e privados aos direitos fundamentais, especificamente à educação inclusiva, por meio da pesquisa bibliográfica.

\section{O AUTISMO E AS NECESSIDADES EDUCACIONAIS DO ALUNO AUTISTA: ÊNFASE NA PRESENÇA DO MONITOR EM SALA DE AULA}

O transtorno do Espectro Autista engloba diversas síndromes, que compreendem os níveis de autismo, caracterizados pelas dificuldades na interação social e problemas na constituição do "eu", na confluência do psíquico e do somático. ${ }^{1}$ Consideram-se síndromes porquanto existe uma pluralidade de sintomas e já nos primeiros anos de vida o diagnóstico pode ser formado. Pelo conceito clássico de Kanner, o déficit social é questão preponderante para o diagnóstico ${ }^{2}$, considerando o prejuízo na interação.

A dificuldade em comunicação pode consistir na produção da linguagem sem a interpretação padrão ${ }^{3}$, ou seja, na relação do autista com o meio, em diferentes níveis (entre o autismo não verbalizado - grave - e o autismo leve). Enquanto as ciências da saúde pesquisam as causas e tratamentos para o autismo, considerando as diversas fontes, com o crescente número de casos, aumenta, outrossim, a necessidade de informação da sociedade a respeito do que é o autismo e o debate social sobre os direitos do autista ${ }^{4}$, uma vez que se trata de uma deficiência com estereotipias e necessidades diferenciadas.

Cada aluno autista tem inúmeras particularidades (heterogeneidade interindividual), não existindo um método específico para o diagnóstico e tratamento ${ }^{5}$, o que deve ser observado no caso concreto. Nesses termos, a educação auxilia o autista a sair de seu universo, diante das adversidades da vida, cuja interação social pode vir a afastar. ${ }^{6} \mathrm{O}$ que se busca - para o autista e para a sociedade - é o seu bemestar, a inclusão e a diversidade, visando o desenvolvimento de todos os alunos. Tanto a educação do indivíduo quanto o diagnóstico de

\footnotetext{
${ }^{1}$ ALI, Sami. Pensar o somático: Imaginário e patologia. São Paulo: Casa do Psicólogo, 1995. p. 16.

${ }^{2}$ CAMPANARIO, Isabela Santoro. Espelho, espelho meu: a psicanálise e o tratamento precoce do autismo e outras psicopatologias graves. Salvador: Algama, 2008. p. 35-36.

${ }^{3}$ LEON, Viviane Costa de et al. A especificidade da compreensão metafórica em crianças com autismo. Psico, Porto Alegre, PUCRS, v. 38, n. 3, p. 269-277, set./dez. 2007. p. 275.

${ }^{4}$ ARAUJO, Gabriela de; et al. Panorama das questões envolvendo psicanálise e autismo na França: dar a palavra aos autistas. APPOA, p. 59-60, abr./mai. 2013.

${ }^{5}$ MARION, Leboyer. Autismo infantil: fatos e modelos. Campinas: Papirus, 2007. p. 29.

${ }^{6}$ TUSTIN, Frances. Barreiras autistas em pacientes neuróticos. Porto Alegre: Artes Médicas, 1990. p. 43.
} 
autismo se dão ainda na infância, razão pela qual a educação é um dos principais meios de intervenção ${ }^{7}$, em que se propõe a interação com o diferente. $^{8}$

Para isso, as técnicas aplicadas, o material didático utilizado e as alterações na rotina devem focar as habilidades e deficiências do autista em sala de aula, com ênfase no seu comportamento. ${ }^{9}$ Conceder um acompanhante específico ao aluno autista muda a realidade da comunidade escolar, tendo em vista as diferentes necessidades do grupo e as pluralidade de técnicas que podem ser adotadas, tais como o método Treatment and Education of Autistic and Related Communication Handicapped Children (TEACH) e o método Applied Behavior Analysis $(\mathrm{ABA})^{10}$, o que se dá por meio do acompanhante especializado.

Desse modo se estrutura a noção de comunidade terapêutica, em que o grupo "se desenvolve", fazendo com que a intervenção do acompanhante especializado, por meio de sua prática que combina diversas metodologias ${ }^{11}$, a rotina do autista e a interação com o meio seja desenvolvida. Destarte, o que se verifica é que a interação do autista com o meio que o cerca se faz pela mediação de outra pessoa, ora na figura de sujeito, ora na figura de objeto, dependendo do

\footnotetext{
${ }^{7}$ BRANDÃO, Paulo Cezar D'Avila. A criança com problemas e a escola maternal. In: CENTRO LYDIA CORAT. Escritos da criança. Porto Alegre: Centro Lydia Coriat, 2011. p. 35.

JERUSALINSKY, Alfredo. Psicanálise $e$ Desenvolvimento Infantil: um enfoque transdisciplinar. Porto Alegre: Artes e Ofícios, 2010. p. 150.

${ }^{9}$ BARRETO, Kleber Duarte. Uma proposta de visão ética no acompanhamento terapêutico. In: EQUIPE DE ACOMPANHANTES TERAPÊUTICOS DO HOSPITALDIA “A CASA" (Org). Crise e Cidade: Acompanhamento terapêutico. São Paulo: EDUC, 1998. p. 263.

10 BRASIL. Ministério da Educação. Secretaria de Educação Especial. Educação Infantil: saberes e prática da inclusão: dificuldades acentuadas de aprendizagem autismo. Brasília, 2003.

${ }^{11}$ PALOMBINI, Analice de Lima; et al. Acompanhamento Terapeutico na Rede Pública: A clínica em movimento. Porto Alegre: Editora UFRGS, 2004. p. 87.
}

grau de espectro de autismo ${ }^{12}$, o que denota a eficiência do monitor.

Em decorrência disso, vislumbra-se além da necessidade da presença do monitor em sala de aula, a importância da existência de um planejamento do serviço de orientação e material didático aplicável ao aluno autista. Tais aspectos encontram-se legitimados pela Lei número 12.764 de $2012^{13}$, ao dispor sobre o direito do acompanhante especializado em sala de aula. De qualquer sorte, independente se ensino público ou privado, o direito à educação inclusiva está esculpido em nosso ordenamento jurídico, valorizando-se, concernente ao aluno autista, a educação terapêutica. ${ }^{14}$

\section{O DIREITO À EDUCAÇÃO INCLUSIVA COMO DIREITO FUNDAMENTAL}

No âmbito jurídico, o direito à educação inclusiva compreende um direito fundamental, sendo estudo que está em constante movimento, pelo caráter histórico e social, devendo sua efetividade ser analisada pelo escopo da legislação programática ${ }^{15}$, implicando no estudo das teorias de interpretação constitucional. Entende-se que é por meio da informação e debate que se chegará à análise desse direito, considerando o modelo constitucional

${ }^{12}$ CUNHA, Eugênio. Autismo e Inclusão: psicopedagogia e práticas educativas na escola e na família. Rio de Janeiro: Wak, 2014. p. 55.

13 BRASIL. Lei $n^{\circ}$ 12.764, de 27 de dezembro de 2012. Disponível em:

<http://www.planalto.gov.br/ccivil_03/_ato2011-

2014/2012/lei/112764.htm>. Acesso em: 07 abr. 2016.

${ }^{14}$ BASTOS, Marise Bartolozzi; KUPFER, Maria Cristina Machado. A escuta de Professores no trabalho de inclusão escolar de crianças psicóticas e autistas. Estilos da clínica, v. 15, n. 1, p. 117, 2010.

15 TAVARES, André Ramos. Princípios Constitucionais. In: MARTINS, Ives Gandra; MENDES, Gilmar Ferreira; NASCIMENTO, Carlos Valder (Coord.). Tratado de Direito Constitucional, v. 1. São Paulo: Saraiva, 2010. p. 410. 
brasileiro 16 , ocasião em que a constitucionalização abrangente coopera para a jurisdicionalização da questão.

A igualdade material pretendida se dá por meio da redistribuição justa dos recursos sociais, considerando uma postura cooperativa entre sociedade e Estado ${ }^{17}$ com a finalidade de proporcionar a execução de medidas que cooperem com a educação inclusiva. Assim, a legislação, execução e a própria justiça estão vinculadas aos ditames estabelecidos pela legislação programática concernentes à educação inclusiva, considerada a hipótese de eficácia vinculativa. $^{18}$

Há uma ampla concessão de direitos (pelo Poder Judiciário), aplicáveis tanto para a rede de ensino pública (eficácia vertical) quanto para rede de ensino privada (eficácia horizontal), razão pela qual o debate envolve a vinculação dos sujeitos aos direitos fundamentais. 19 Dentre os fundamentos que irradiam no sistema, o da dignidade da pessoa humana ${ }^{20}$, como norma central do ordenamento jurídico, infere a convergência do direito público e privado com a Constituição Federal. $^{21}$

16 QUEIROZ, Maria do Socorro Azevedo de. Judicialização dos direitos sociais prestacionais: a efetividade pela interdependência dos Direitos Fundamentais na Constituição Brasileira. Curitiba: Juruá, 2011. p. 51.

${ }^{17}$ NETO, Claudio Pereira de Souza. Teoria Constitucional e Democracia Deliberativa: um estudo sobre o papel do direito na garantia das condições para a cooperação na deliberação democrática. Rio de Janeiro: Renovar, 2006. p. 169.

${ }^{18}$ CARRION, Eduardo Kroeff Machado. As utopias da realidade constitucional: nos trilhos do contraponto neoliberal. In: CARRION, Eduardo. A universalidade dos Direitos Humanos: realidade ou projeto? Porto Alegre: Núria Fabris Editora, 2014. p. 52.

19 DIMOULIS, Dimitri; MARTINS, Leonardo. Teoria Geral dos Direitos Fundamentais. 4. ed. São Paulo: Atlas, 2012. p. 98.

${ }^{20}$ SARLET, Info Wolfgang. Dignidade da Pessoa Humana e Direitos Fundamentais na Constituição Federal de 1988. Porto Alegre: Livraria do Advogado, 2004. p. 69-70.

21 DUQUE, Marcelo Schenk. Direito Privado $e$ Constituição: Drtittwirkung dos direitos fundamentais.
Considerando que a realização da educação inclusiva demanda recursos financeiros para a execução, enfrenta-se um dos maiores óbices diante da competência orçamentária do legislador e livre iniciativa privada. ${ }^{22}$ Por isso a dificuldade de análise do caso concreto, já que entre normas constitucionais originárias não há hierarquia ${ }^{23}$, oportunidade em que a Constituição Federal passa a ter um aspecto valorativo, esculpido em princípios como o da máxima efetividade da constituição e da reserva do possível ${ }^{24}$, cuja interpretação é sistêmica, fundada na unidade de princípios e regras, evitando-se contradições ${ }^{25}$, em relação à aplicabilidade dos direitos fundamentais.

\section{DIREITOS SOCIAIS DIANTE DA RESERVA DO POSSÍVEL E DA MÁXIMA EFETIVIDADE DA CONSTITUIÇÃO FEDERAL}

Evidenciada a litigiosidade que envolve o direito fundamental à educação inclusiva do autista, o estudo se tece diante de um Estado Social em crise, em que as garantias constitucionais não são $\operatorname{cumpridas}^{26}$, tanto pelo

Construção à luz dos contratos de consumo. São Paulo: Revista dos Tribunais, 2013. p. 197.

${ }^{22}$ LEIVAS, Paulo Gilberto Cogo. Teoria dos Direitos Fundamentais Sociais. Porto Alegre: Livraria do Advogado, 2006. p. 99.

${ }^{23}$ MIRANDA, Jorge. Manual de Direito Constitucional, v. II. 2 ed. Coimbra: Limitada, 1983. p. 291.

24 BARROSO, Luis Roberto. Neoconstitucionalismo $e$ constitucionalização do Direito. Disponível em: <http://www.luisrobertobarroso.com.br/wp

content/themes/LRB/pdf/neoconstitucionalismo_e_constit ucionalizacao_do_direito_pt.pdf>. Acesso em: 25 mar. 2016. p. 10.

${ }^{25}$ BASTOS, Celso Ribeiro. Hermenêutica e interpretação Constitucional. 2. ed. São Paulo: Instituto Brasileiro de Direito Constitucional, 1999. p. 102.

26 SAAVEDRA, Giovani Agostini. Jurisdição $e$ democracia: uma análise a partir das teorias de Jürgen Habermas, Robert Alexy, Ronald Dworkin e Niklas Luhmann. Porto Alegre: Livraria do Advogado, 2006. p. 77-78. 
Estado quanto pelo particular. ${ }^{27} \mathrm{~A}$ educação inclusiva impõe, no caso da criança autista, o dispêndio com um profissional específico para seu apoio, redução de número de alunos por turma e material didático diferenciado.

Nesse passo, se questiona se é possível uma limitação a um bem jurídico em decorrência da ausência de financiamento, em face da aplicabilidade imediata. ${ }^{28} \mathrm{O}$ Supremo Tribunal Federal pondera a reserva do possível com fundamento na supremacia da dignidade da pessoa humana, o que legitima a intervenção judicial $^{29}$, posto que avalia o que deixaria de ser feito e o que está sendo feito com os recursos financeiros disponíveis.

A utilização do princípio da reserva do possível atende, em última análise, eventual desperdício do dinheiro público, já que diretamente interligados à conjuntura econômica do Estado. Com isso, aufere-se a máxima efetividade da Constituição Federal ${ }^{30}$, que proporciona a igualdade material, com a redistribuição de prioridades, refletindo acerca da alta demanda em contraposição a escassez de recursos. ${ }^{31}$

\footnotetext{
27 CANOTILHO, José Joaquim Gomes. Estudos sobre Direitos Fundamentais. São Paulo: Coimbra Editora, 2008. p. 254-255.

28 SARLET, Ingo Wolfgang. A eficácia dos direitos fundamentais: uma teoria geral dos direitos fundamentais na perspectiva constitucional. Porto Alegre: Livraria do Advogado, 2010. p. 269.

${ }^{29}$ SARLET, Ingo Wolfgang. As dimensões da dignidade da pessoa humana: construindo uma compreensão jurídico constitucional necessária e possível. In: SARLET, Ingo Wolfgang (Org.). Dimensões da Dignidade: Ensaios de filosofia do Direito e Direito Constitucional. Porto Alegre: Livraria do Advogado, 2005. p. 29.

${ }^{30}$ SANTIN, Janaína Rigo; MORAIS, Jose Luis Bolzan de. Constituição e direitos humanos. Ou: só é possível dignidade na Constituição? In: MELGARÉ, Plínio; FILHO, Agassiz Almeida (org). Dignidade da pessoa humana: fundamentos e critérios interpretativos. São Paulo: Malheiros Editores, 2010. p. 426.

${ }^{31}$ LEAL, Rogério Gesta. Direito fundamentais em Foco: nunca é o bastante. Porto Alegre: Núria Fabris Editora, 2012. p. 156.
}

Portanto, as normas constitucionais devem ser interpretadas na dimensão que maior eficácia lhe seja dada, aproximando a aplicação e a interpretação da Constituição Federal. ${ }^{32}$ Assim, repisa a força normativa da Constituição, ao considerar que toda a norma constitucional possui um mínimo de eficácia. ${ }^{33}$

A máxima efetividade da Constituição Federal é, assim como a reserva do possível, fundamento para a jurisdicionalização dos conflitos que envolvam direitos sociais ${ }^{34}$, sendo um mandado de otimização. É um limite ao poder de reforma que visa atingir o conteúdo da prestação dos direitos sociais, intimamente relacionado com a segurança jurídica e dignidade da pessoa humana. ${ }^{35}$ Para a educação inclusiva do autista, a máxima efetividade compreende atenção e analise de suas necessidades especiais, sendo o mínimo necessário para o desenvolvimento. ${ }^{36}$

\section{AÇÕES AFIRMATIVAS RELATIVAS À EDUCAÇÃO INCLUSIVA DO AUTISTA}

A expressão "ações afirmativas" é utilizada no plural porque envolve um conjunto de ações,

32 SARLET, Ingo Wolfgang. Linhas Mestras da Interpretação constitucional. In: SARLET, Ingo Wolfgang; MARINONI, Luiz Guilherme; MITIDIERO, Daniel. Curso de Direito Constitucional. 2 ed. São Paulo: Revista dos Tribunais, 2013. p. 227.

33 MACEDO, Regina Maria; FERRARI, Nery. Normas constitucionais programáticas: normatividade, operatividade e efetividade. São Paulo: Revista dos Tribunais, 2001. p. 119.

34 SCHÄFER, Jairo. Classificação dos direitos fundamentais: do sistema geracional ao sistema unitário uma proposta de compreensão. 2. ed. Porto Alegre: Livraria do Advogado, 2013. p. 80-81.

35 SARLET, Ingo Wolfgang. A eficácia dos Direitos Fundamentais. Porto Alegre: Livraria do Advogado, 2007. p. 437.

${ }^{36}$ KREL, Andreas J. Realização dos direitos fundamentais sociais mediante controle judicial da prestação dos serviços públicos básicos (uma visão comparativa). Revista de Informação Legislativa, Brasília, ano 36, n. 144, 2009. p. 247. 
que abrange setor público e privado, com a finalidade de adotar medidas diferenciadoras que proporcionem um tratamento isonômico. ${ }^{37} \mathrm{As}$ ações afirmativas podem se respaldar de meios temporários que objetivam a integração ${ }^{38}$, promovendo uma sociedade diversificada e consciente dessa diversidade, atuando no acesso à educação inclusiva, ou até mesmo, diante da sua má prestação. Em vista do tratamento prestacional positivo em favor de determinados grupos, as ações afirmativas ganharam força no Brasil na última década.

Dá-se conta disso pela recente legislação Estatuto da Pessoa com Deficiência (Lei $\mathrm{n}^{\mathrm{o}}$ 13.146 de 2015) ${ }^{39}$, por exemplo, bem assim Lei ${ }^{\circ}$ 12.764 de $2012^{40}$, que classificou o autismo como deficiência, o que trouxe benefícios no amparo social dessas pessoas, valendo-se da igualdade substancial ou material. ${ }^{41}$ Esse tratamento jurídico incentiva a igualdade de oportunidade (no termo legislativo) e a igualdade de resultado (ações para execução da legislação) ${ }^{42}$, visando

\footnotetext{
${ }^{37}$ STRECK, Lenio Luiz. Hermenêutica jurídica e $(m)$ crise: uma exploração hermenêutica da construção do Direito. 3. ed. Porto Alegre: Livraria do Advogado, 2001. p. 283.

${ }^{38}$ NETO, Vicente Higino. Ações afirmativas: razão cínica ou igualdade substancial? In: PIOVESAN, Flávio. Direitos Humanos: fundamento, proteção e implementação. Curitiba, 2008. p. 700.

39 BRASIL. Lei $n^{o}$ 13.146, de 6 de julho de 2015. Disponível em:

<http://www.planalto.gov.br/ccivil_03/_Ato20152018/2015/Lei/L13146.htm>. Acesso em: 07 abr. 2016.

${ }^{40}$ BRASIL. Lei $n^{\circ}$ 12.764, de 27 de dezembro de 2012. Disponível em:

<http://www.planalto.gov.br/ccivil_03/_ato2011-

2014/2012/lei/112764.htm>. Acesso em: 07 abr. 2016.

${ }^{41}$ GOMES, Joaquim B. Barbosa. A recepção do instituto da ação afirmativa pelo direito constitucional brasileiro. Revista de Informação Legislativa, Brasília, ano 38, n. 151, p. 129-252, jul./set. 2001. Disponível em: <http://www2.senado.leg.br/bdsf/item/id/705>. Acesso em: 07 abr. 2016.

42 MORAES, Alexandre de. Direitos Humanos Fundamentais: teoria geral: comentários aos arts. $1^{\circ}$ a $5^{\circ}$ da Constituição da República Federativa do Brasil: doutrina e jurisprudência. São Paulo: Atlas, 2005. p. 81.

${ }^{43}$ GOMES, Joaquim Benedito Barbosa. Ação afirmativa e princípio da igualdade: o direito como instrumento de
}

evitar discriminações principalmente aplicáveis aos direitos sociais. ${ }^{43}$

Em face das necessidades do aluno, a educação especial pode ser complementar, sendo que a regra é a inclusão do aluno em sala regular de ensino. ${ }^{44}$ Do ponto de vista jurídico, há convergência entre o público e o privado que integram o tratamento multidisciplinar do autista. ${ }^{45}$ Dentre o rol de ações afirmativas, a determinação de prevalência da educação inclusiva está disposta no texto constitucional, fulcro artigo 208, III. $^{46}$

Nesse escopo, em 1996, a Lei de Diretrizes e Bases da Educação, Lei no 9.394 de $1996^{47}$, recepcionou a Declaração de Salamanca a respeito da educação inclusiva. O Estatuto da Pessoa com Deficiência (Lei no 13.146 de 2015) ${ }^{48}$ é que trata da vedação dos repasses dos custos extras aos alunos portadores de deficiência, negativa de matrícula, dentre outras questões que delimitam e exemplificam disposição da Lei de Diretrizes e Bases da Educação. A Lei no 12.764

transformação social: a experiência dos EUA. Rio de Janeiro: Renovar, 2001. p. 143.

44 OLIVEIRA, Valtênio Paes de. LDBEN Comentada: interpretação da Lei de Diretrizes e Bases da Educação Nacional e do Plano Nacional de Educação. Porto Alegre: Redes, 2009. p. 109.

${ }^{45}$ NETO, Eugênio Facchini. Reflexões histórico-evolutivas sobre a constitucionalização do direito Privado. In: SARLET, Ingo Wolfgang (Org). Constituição, Direitos Fundamentais e Direito Privado. Porto Alegre: Livraria do advogado, 2003. p. 26.

46 “Art. 208. O dever do Estado com a educação será efetivado mediante a garantia de: III - atendimento educacional especializado aos portadores de deficiência, preferencialmente na rede regular de ensino." (BRASIL. Constituição da República Federativa do Brasil de 1988. Disponível em:

<http://www.planalto.gov.br/ccivil_03/Constituicao/Consti tuicaoCompilado.htm>. Acesso em: 07 abr. 2016.)

${ }^{47}$ BRASIL. Lei $n^{\circ}$ 9.394, de 20 de dezembro de 1996. Disponível em:

<http://www.planalto.gov.br/ccivil_03/leis/L9394.htm>. Acesso em: 07 abr. 2016.

48 BRASIL. Lei $n^{o}$ 13.146, de 6 de julho de 2015. Disponível em:

<http://www.planalto.gov.br/ccivil_03/_Ato2015-

2018/2015/Lei/L13146.htm>. Acesso em: 07 abr. 2016. 
de $2012^{49}$ especifica quanto ao autista, trazendo as ações a serem realizadas pelo Poder Público a fim de proporcionar maior proteção como o faz no artigo $3^{\circ}$, parágrafo único, no que tange ao direito a educação, repisando o direito ao acompanhante especializado.

Convém, no entanto, analisar a questão da "comprovada necessidade" estabelecida em lei, que, a despeito do Decreto $\mathrm{n}^{\circ} 8.368$ de 2014, pode ser questionada pela comunidade escolar, impondo estudos prévios e um constante acompanhamento do aluno, visando à qualidade de vida do autista. ${ }^{50}$ Além do mais, quando há educandos com necessidades especiais, indica-se que o número de alunos na classe regular seja reduzido. No estado de São Paulo a Lei Estadual $\mathrm{n}^{\mathrm{o}} 15.830$ de $2015^{51}$ limita 20 alunos por turma. No estado do Rio Grande do Sul, o parecer $n^{\circ} 56$ de 2006 da Comissão Especial de Educação Especial $^{52}$ também limita a 20 alunos por turma e a presença de no máximo três alunos especiais em cada turma.

Por fim, destaca-se a responsabilidade do Poder Público em fornecer informação relativa ao transtorno e suas implicações, o que é o início para que se afaste o sentimento de incompletude e desordem que circunda a educação inclusiva. ${ }^{53}$ Ademais, em contrapartida à atual legislação a

${ }^{49}$ BRASIL. Lei $n^{o}$ 12.764, de 27 de dezembro de 2012. Disponível

<http://www.planalto.gov.br/ccivil_03/_ato2011-

2014/2012/lei/112764.htm>. Acesso em: 07 abr. 2016.

${ }^{50}$ MORAIS, Jose Luis Bolzan de. Do direito social aos interesses transindividuais: o estado e o direito na ordem contemporânea. Porto Alegre: Livraria do Advogado, 1996. p. 182.

51 “Autoriza o Poder Executivo a limitar o número de alunos nas salas de aula do ensino fundamental e médio que têm matriculados alunos com necessidades especiais." SÃO PAULO. Lei $n^{\circ} 15.830$, de 15 de junho de 2015. Disponível em:

<http://www.al.sp.gov.br/repositorio/legislacao/lei/2015/le i-15830-15.06.2015.html>. Acesso em: 07 abr. 2016.

52 RIO GRANDE DO SUL. Conselho Estadual de Educação. Parecer 0056 de 06 de janeiro de 2006. Disponível

<http://www.ceed.rs.gov.br/conteudo/10127/parecern\%C2\%BA-0056-2006>. Acesso em: 07 abr. 2016. respeito do tema, a crescente jurisdicionalização demonstra o abismo existente entre a teoria dos direitos sociais e sua aplicação, diferenciando o plano da universalização dos direitos fundamentais do plano da multiplicação desses direitos, sendo o último relativo à sua aplicabilidade ${ }^{54}$, o que leva ao debate do controle de constitucionalidade.

\section{A EDUCAÇÃO INCLUSIVA COM A PRESENÇA DE MONITOR NO ENSINO PÚBLICO}

Pelo exposto, depreende-se que é dever do Estado garantir, observada a gratuidade do ensino público, a adequada formação do ambiente escolar, com ênfase na figura do monitor para o aluno autista. ${ }^{55}$ Analisando o direito pleiteado e os princípios que o elucidam, máxime no princípio da proporcionalidade, é difícil aventar alguma hipótese em que o Poder Público seja destituído desse dever. ${ }^{56} \mathrm{O}$ Estado Social que a Constituição Federal propõe, por meio da redistribuição dos lucros sociais ${ }^{57}$, no entanto, não acompanha a eficiência de nossos administradores públicos.

Para esse raciocínio, o princípio da proporcionalidade deve reger eventuais restrições tendo em vista o objeto legal ${ }^{58}$ e considerando os

${ }^{53}$ DOUZINAS, COSTAS. O fim dos direitos humanos. São Leopoldo: Editora Unisinos, 2009. p. 337.

${ }^{54}$ BOBBIO, Norberto. A era dos direitos. Rio de Janeiro: Campus, 1992. p. 67.

55 CARVALHO, Sandra Silveira. Acompanhamento Terapêutico: que clínica é essa? São Paulo: Annablume, 2004. p. 41.

56 SCHÄFER, Jairo. Classificação dos direitos fundamentais: do sistema geracional ao sistema unitário: uma proposta de compreensão. 2. ed. Porto Alegre: Livraria do Advogado, 2013. p. 45-46.

${ }^{57}$ PORTO, Pedro Rui da Fontoura. Direitos Fundamentais Sociais: considerações acerca da legitimidade política a processual do Ministério Público e do sistema de justiça para a sua tutela. Porto Alegre: Livraria do Advogado, 2006. p. 57.

58 ROSAS, Roberto. Proporcionalidade no controle da Constitucionalidade. In: ROCHA, Fernando Luiz Ximenes; MORAES, Filomeno (Coord.). Direito Constitucional Contemporâneo. Belo Horizonte: Del Rey, 2005. p. 719. 
três elementos que constituem o princípio - quais sejam a adequação ou idoneidade, a necessidade e a proporcionalidade em sentido estrito ${ }^{59}$-, cabe, no presente caso, o planejamento de uma ordem econômica justa. ${ }^{60}$ Outrossim, a vinculação aos direitos fundamentais abrange todos os Poderes do Estado (Legislativo na realização das leis, Judiciário em seus julgados e Executivo pautando suas ações) ${ }^{61}$

Assim, como já aventado, a problemática não se limita à ausência de recursos para o fornecimento de uma educação inclusiva, porquanto pesquisa a conformidade do orçamento com as demais normas constitucionais. ${ }^{62}$ Quando do enfrentamento da questão perante a prestação pelo Poder Público, sendo o princípio da reserva do possível a principal fundamentação, cogita-se a hipótese de levar a discussão para o aspecto das finanças públicas. ${ }^{63}$

Nesse sentido, implica a análise da real necessidade e oportunidade, ainda que alguns setores mereçam mais atenção do que outros, diante da essencialidade de alguns direitos, como a saúde, educação e previdência. A eficiência é um dever do Estado e um direito do cidadão e sua não observância afronta os direitos fundamentais, seja de modo direto ou indireto. ${ }^{64}$

Dentre as ações afirmativas elencadas na Lei $\mathrm{n}^{\mathrm{o}} 12.764$ de 2012, a educação com intermédio do monitor constitui o cerne da questão social do indivíduo autista razão pela qual

59 PAULA, Felipe de. A (de)limitação dos direitos fundamentais. Porto Alegre: Livraria do Advogado, 2010. p. 100.

60 CALIENDO, Paulo. Reserva do possível, direitos fundamentais e tributação. In: SARLET, Ingo Wolfgang; TIMM, Luciano Benetti (Org.). Direitos Fundamentais: orçamento e "reserva do possível". 2. ed. Porto Alegre: Livraria do Advogado, 2010. p. 178-179.

61 SARLET, Ingo Wolfgang. A eficácia dos direitos fundamentais: uma teoria geral dos direitos fundamentais na perspectiva constitucional. Porto Alegre: Livraria do Advogado, 2012. p. 377-378.

62 BREUS, Thiago Lima. Políticas Públicas no Estado Constitucional: problemática da concretização dos direitos fundamentais pela Administração Pública brasileira contemporânea. Belo Horizonte: Fórum, 2007. p. 239-241. integram o conceito do mínimo existencial para o autista. ${ }^{65}$ Nesse diapasão, as cláusulas gerais estabelecidas na Constituição Federal possuem interpretação extensiva, porquanto alargam o rol de direitos fundamentais previstos ${ }^{66}$ sob o escopo da dignidade da pessoa humana ${ }^{67}$, devendo ser o pressuposto de análise quanto à eficácia vertical dos direitos fundamentais.

\section{A EDUCAÇÃO INCLUSIVA COM A PRESENÇA DE MONITOR NO ENSINO PRIVADO}

No que diz respeito às instituições de ensino privado, o debate envolve a eficácia horizontal dos direitos fundamentais, pela teoria da eficácia indireta. Os litígios relacionados à educação inclusiva no ensino privado correspondem ao repasse dos custos da inclusão ao familiar do aluno com espectro autismo, a obrigatoriedade da matrícula e a discricionariedade da escola para inserir ou escolher o acompanhante na classe regular, em face da autonomia privada. ${ }^{68}$

$\mathrm{O}$ direito à educação inclusiva para o aluno autista e o direito à diversidade que abrange a comunidade escolar devem ser analisados também diante do princípio da legalidade,

63 PEDERIVA, João Henrique. Orçamento público e relações entre os poderes. In: MESSENBERG, Débora et al. (Org.). Estudos Legislativos: 20 anos da Constituição Brasileira. Brasília, 2010. p. 374-375.

64 TORRES, Marcelo Douglas de Figueiredo. Estado, democracia e administração pública no Brasil. Rio de Janeiro: Editora FGV, 2004. p. 75.

${ }^{65}$ NETO, Eurico Bitencourt; NETTO, Luisa Cristina Pinto. Direito Administrativo e direitos fundamentais: diálogos necessários. Belo Horizonte: Fórum, 2012. p. 169-170.

${ }^{66}$ GOUVEIA, Jorge Barcelar. Os direitos fundamentais atípicos. Lisboa: Aequitas Editorial Notícias, 1995. p. 93.

67 LELLIS, Maximino. Princípios constitucionais do ensino. São Paulo: Lexia, 2011. p. 186.

${ }^{68}$ SARMENTO, Daniel. Direitos Fundamentais e Relações Privadas. Rio de Janeiro: Lumen Juris, 2008. p. 243-244. 
considerada função pública exercida ${ }^{69}$ pela instituição privada. A eficácia dos direitos fundamentais nas relações privadas é esculpida no pretexto social dos direitos fundamentais ${ }^{70}$, havendo um vínculo de imposição dos direitos fundamentais estabelecido entre particulares e legislação aplicável. ${ }^{71}$

Substancia-se no direito à diversidade, que também deve ser observada dentre as relações privadas. ${ }^{72}$ Uma vez que os direitos fundamentais são meios de interpretação, denota-se o aspecto hermenêutico que a dimensão dos direitos fundamentais possui em face do direito privado. ${ }^{73}$ As ações da entidade privada esculpem-se pela questão política e social de suas decisões e não somente a econômica, sendo que esta última tem suas perspectivas alteradas pelo aspecto social ${ }^{74}$, cabendo a interpretação no contexto axiológico da norma. ${ }^{75}$

Contrapõem-se as teorias entre a eficácia mediata e imediata dos direitos fundamentais perante as relações particulares ${ }^{76}$, considerando que se trata do espaço público não estatal..$^{77} \mathrm{Em}$ razão disso, o conceito de valor comunitário permanente $^{78}$, em que os custos devem ser compartilhados na planilha de custo, já que a educação inclusiva não deve ser ônus do aluno

\footnotetext{
${ }^{69}$ BONTEMPO, Alessandra Gotti. Os direitos Sociais e a discricionariedade do administrador na implementação de políticas públicas. In: PIOVESAN, Flávia; IKAWA, Daniela (Coord). Direitos Humanos: fundamento, proteção e implementação: perspectivas e desafios contemporâneos. Curitiba: Juruá, 2008.

${ }^{70}$ BARROSO, Luís Roberto. O direito constitucional e a efetividade de suas normas: limites e possibilidades da Constituição brasileira. 3. ed. Rio de Janeiro: Renovar, 1996. p. 82-83.

${ }^{71}$ DUQUE, op. cit. p. 201.

${ }^{72}$ MARQUES, Claudia Lima; MIRAGEM, Bruno. O novo direito privado e a proteção dos vulneráveis. São Paulo: Revista dos Tribunais, 2012. p. 184.

${ }^{73}$ SARMENTO, Daniel. Direitos Fundamentais e Relações Privadas. Rio de Janeiro: Lumen Juris, 2008. p. 107-108.

${ }^{74}$ ROBLES, Gregorio. Os direitos fundamentais e a ética na sociedade atual. Barueri: Manole, 2005. p. 97.

75 TEPEDINO, Gustavo. Premissas Metodológicas para a Constitucionalização do Direito Civil. In: TEPEDINO,
}

autista, mas sim objeto de investimento do sistema de educação.

Em síntese, tais litígios, por envolverem relações privadas, impõem uma interpretação sistêmica, com a ponderação dos princípios expostos, por meio da integração do modelo de convergência entre Direito Privado e Constituição, em vista da máxima efetividade do texto constitucional. ${ }^{79}$ Por fim, tratando-se da educação inclusiva no ensino privado, não se pode deixar de trabalhar a respeito da $\mathrm{ADI} n^{\circ}$ 5357, que fixou entendimento do Plenário relativo à matéria.

\section{ESTUDO DE CASO: AÇÃO DIRETA DE INCONSTITUCIONALIDADE 5.357}

A educação inclusiva já era matéria aventada nos tribunais estaduais, sendo levada aos tribunais superiores por litígios individuais. Com a promulgação do Estatuto da Pessoa com Deficiência o debate foi levado ao Supremo Tribunal Federal por meio de ação direta de inconstitucionalidade número $5.357^{80}$, interposta pela Confederação Nacional dos Estabelecimentos de Ensino. A postulação de inconstitucionalidade diz respeito ao $\S 1^{\mathrm{o}}$ do artigo 28 e artigo 30, caput, da Lei 13.146/2015 ${ }^{81}$,

Gustavo. Temas de Direito Civil. Rio De Janeiro: Renovar, 2001. p. 21.

76 FILHO, Manoel Gonçalves Ferreira. Comentários à Constituição brasileira de 1988. São Paulo: Saraiva, 1997. p. 84.

${ }^{77}$ MALISKA, Marcos Augusto. $O$ direito à educação e a constituição. Porto Alegre: Sergio Antonio Fabris Editor, 2001. p. 190-197.

78 BARROS, Sérgio Resende de. Direitos Humanos: paradoxo da civilização. Belo Horizonte: Del Rey, 2003. p. 403-404.

${ }^{79}$ DUQUE, op. cit., p. 403-404.

${ }^{80}$ BRASIL. Supremo Tribunal Federal. Ação Direta de Inconstitucionalidade ${ }^{\circ}$ 5.357. Relator: Min. Edson Fachin, Disponível em:

<http://www.jusbrasil.com.br/diarios/documentos/3205104 57/andamento-do-processo-n-5357-acao-direta-de inconstitucionalidade-05-04-2016-do-stf?ref=topic_feed>. Acesso em: 07 abr. 2016.

81 BRASIL. Lei $n^{o}$ 13.146, de 6 de julho de 2015. Disponível em: 
que, em síntese, trata da obrigatoriedade de matrícula e a impossibilidade do repasse dos custos em decorrência da inclusão do aluno deficiente. A parte autora argumenta que as determinações legais do referido diploma legal levariam ao encerramento das atividades das escolas privadas, tendo em vista o custo elevado.

A questão não se trata de inconstitucionalidade propriamente dita ${ }^{82}$, porque não há hierarquia entre os princípios constitucionais. Diz respeito à hermenêutica constitucional e ponderação dos princípios, com enfoque na dinâmica social: num país subdesenvolvido, com larga margem de desigualdades sociais, há uma banalização dos direitos sociais, posto que as sanções em caso de não observância, na maioria das vezes, são mais vantajosas no aspecto econômico do que o cumprimento da disposição, como a manutenção/aceitação do aluno em sala de aula.

Ainda que não se fale de uma constitucionalização do direito privado, busca-se a harmonia do sistema, com a interpretação sistemática das normas, que almejam a mesma finalidade. ${ }^{83}$ Os argumentos que embasam a Ação Direta de Inconstitucionalidade, por outro lado, reduzem um direito fundamental em face de princípios aplicáveis à propriedade privada, por meio de retrocesso legislativo.

A decisão em comento, no entanto, que votou pela improcedência da ação, relaciona a eficácia dos direitos sociais não apenas às prestações do Estado, mas também da atuação dos particulares, com enfoque na "vontade do constituinte" 84 . Portanto, aponta o

<http://www.planalto.gov.br/ccivil_03/_Ato20152018/2015/Lei/L13146.htm>. Acesso em: 07 abr. 2016.

82 REIS, Mauricio Martins. A decisão de inconstitucionalidade: módulo crítico para um tratamento autônomo e homogêneo. In: JOBIM, Marco Félix; FAYET,

Paulo; JOBIM, Geraldo (Org). Controvérsias Constitucionais Atuais. Porto Alegre: Livraria do Advogado, 2014. p. 210.

${ }^{83}$ BARROSO, Luís Roberto. O novo direito constitucional brasileiro: contribuições para a construção teórica e prática posicionamento do Supremo Tribunal Federal em duas perspectivas: a primeira, no que tange a relação entre particulares e os direitos fundamentais; e a segunda, relativamente à função dos direitos sociais e princípios constitucionais que envolvem a pessoa deficiente no sistema constitucional brasileiro.

No que diz respeito ao modelo de interpretação constitucional proposto pelo Supremo Tribunal Federal ${ }^{85}$, a educação inclusiva consiste em uma ação positiva de dupla via, ou seja, cuja atuação cabe a toda sociedade, numa intrínseca relação com a moralidade. ${ }^{86} \mathrm{~A}$ lei objeto de arguição de inconstitucionalidade, na verdade, atendeu todos os preceitos constitucionais, inclusive, no que diz respeito à igualdade e dignidade da pessoa humana. Se assim o é, o direito é uma integridade, composto tanto por regras como princípios. Consequentemente, a garantia e efetividade das ações afirmativas estão dispostas no próprio sistema jurídico, dentro do qual os operadores devem atuar, seja nos casos de lacuna, indeterminação ou antinomia.

\section{CONCLUSÃO}

Considerada a atualidade do tema e a necessidade de pesquisas que envolvam não só a discussão no plano do dever ser, mas também discussões que busquem a eficácia dos direitos sociais, a questão que deve ser debatida pelos operadores do direito, numa perspectiva multidisciplinar. O trabalho pretendeu abranger as principais divergências constitucionais que

da jurisdição constitucional no Brasil. Belo Horizonte: Fórum, 2013. p. 36-37.

${ }^{84}$ BRANDÃO, Rodrigo. O STF e o dogma do legislador negativo. Direito, Estado e Sociedade, n.44, p. 191, jan/jun. 2014.

${ }^{85}$ BARROSO, Luís Roberto, op. cit., p. 36-37.

${ }^{86}$ DWORKIN, Ronald. Levando os direitos a sério. Tradução de Nelson Boeira. São Paulo: Martins Fontes, 2002. p. 43. 
embasam a educação inclusiva, com ênfase da pessoa portadora do espectro autismo, relativamente as suas necessidades educacionais especialíssimas. Pelo exposto, objetiva-se a reflexão sobre o direito à educação e os institutos jurídicos relacionados, porquanto a educação inclusiva do autista, com o fornecimento do acompanhante especializado em sala de aula, trata, em última análise, da máxima efetividade da Constituição, com respaldo na dignidade da pessoa humana.

\section{REFERÊNCIAS}

ALI, Sami. Pensar o somático: imaginário e patologia. São Paulo: Casa do Psicólogo, 1995.

ARAUJO, Gabriela de et al. Panorama das questões envolvendo psicanálise e autismo na França: dar a palavra aos autistas. $A P P O A$, p. 59-60, abr./mai. 2013.

BARRETO, Kleber Duarte. Uma proposta de visão ética no acompanhamento terapêutico. In: EQUIPE DE ACOMPANHANTES TERAPÊUTICOS DO HOSPITAL-DIA “A CASA” (Org). Crise e Cidade: Acompanhamento terapêutico. São Paulo: EDUC, 1998.

BARROS, Sérgio Resende de. Direitos Humanos: paradoxo da civilização. Belo Horizonte: Del Rey, 2003.

BARROSO, Luís Roberto. $O$ direito constitucional e a efetividade de suas normas: Limites e possibilidades da Constituição brasileira. 3. ed. Rio de Janeiro: Renovar, 1996.

. O novo direito constitucional brasileiro: contribuições para a construção teórica e prática da jurisdição constitucional no Brasil. Belo Horizonte: Fórum, 2013.

<http://www.luisrobertobarroso.com.br/wp-

Neoconstitucionalismo e constitucionalização do direito. Disponível em: content/themes/LRB/pdf/neoconstitucionalismo_e_constitucionalizacao_do_direito_pt.pdf $>$. Acessado em: 20 nov. 2016.

BASTOS, Celso Ribeiro. Hermenêutica e interpretação Constitucional. 2. ed. São Paulo: Instituto Brasileiro de Direito Constitucional, 1999.

BASTOS, Marise Bartolozzi; KUPFER, Maria Cristina Machado. A escuta de Professores no trabalho de inclusão escolar de crianças psicóticas e autistas. Estilos da clínica, v. 15, n. 1, p. 117, 2010.

BRANDÃO, Paulo Cezar D'Avila. A criança com problemas e a escola maternal. In: CENTRO LYDIA CORAT. Escritos da criança. 3. ed. Porto Alegre: Centro Lydia Coriat, 2011. p. 35.

BRANDÃO, Rodrigo. O STF e o dogma do legislador negativo. Direito, Estado e Sociedade, n. 44, p. 191, jan/jun. 2014.

BRASIL. Constituição da República Federativa do Brasil de 1988. Disponível em: $<$ http://www.planalto.gov.br/ccivil_03/Constituicao/Constituicao.htm>. Acesso em: 07 abr. 2016

Lei $n^{\circ}$ 12.764, de 27 de dezembro de 2012. Disponível em:

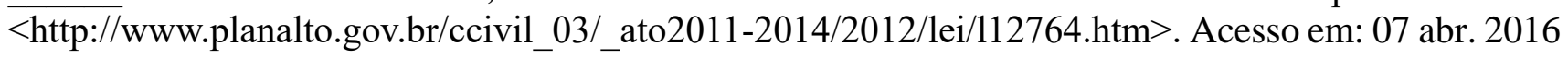


Lei $n^{o}$ 13.146, de 6 de julho de 2015. Disponível em: $<$ http://www.planalto.gov.br/ccivil_03/_Ato2015-2018/2015/Lei/L13146.htm>. Acesso em: 07 abr. 2016

. Ministério da Educação. Secretaria de Educação Especial. Educação Infantil: saberes e prática da inclusão: dificuldades acentuadas de aprendizagem autismo. Brasília, 2003. Disponível em: < http://portal.mec.gov.br/seesp/arquivos/pdf/educacao\%20infantil\%204.pdf $>$. Acessado em: 07 abr. 2016.

BREUS, Thiago Lima. Políticas Públicas no Estado Constitucional: problemática da concretização dos direitos fundamentais pela Administração Pública brasileira contemporânea. Belo Horizonte: Fórum, 2007.

CAMPANARIO, Isabela Santoro. Espelho, espelho meu: a psicanálise e o tratamento precoce do autismo e outras psicopatologias graves. Salvador: Algama, 2008.

CANOTILHO, José Joaquim Gomes. Estudos sobre Direitos Fundamentais. São Paulo: Coimbra Editora, 2008.

. Direito constitucional e teoria da constituição. Portugal: Livraria Almedina, 2001.

CARRION, Eduardo. A universalidade dos Direitos Humanos: realidade ou projeto? Porto Alegre: Núria Fabris Editora, 2014.

CARVALHO, Sandra Silveira. Acompanhamento Terapêutico: que clínica é essa? São Paulo: Annablume, 2004.

CENTRO LYDIA CORAT. Escritos da criança. 3. ed. Porto Alegre: Centro Lydia Coriat, 2011.

CRUZ, Álvaro Ricardo de Souza. O direito à diferença: as ações afirmativas como mecanismo de inclusão social de mulheres, negros, homossexuais e pessoas portadoras de deficiência. Belo Horizonte: Del Rey, 2003.

CUNHA, Eugênio. Autismo e Inclusão: psicopedagogia e práticas educativas na escola e na família. Rio de Janeiro: Wak, 2014.

DIMOULIS, Dimitri; MARTINS, Leonardo. Teoria Geral dos Direitos Fundamentais. 4. ed. São Paulo: Atlas, 2012.

DUQUE, Marcelo Schenk. Direito Privado e Constituição: Drtittwirkung dos direitos fundamentais: construção à luz dos contratos de consumo. São Paulo: Revista dos Tribunais, 2013.

DWORKIN, Ronald. Levando os direitos a sério. Tradução Nelson Boeira. São Paulo: Martins Fontes, 2002.

FILHO, Manoel Gonçalves Ferreira. Comentários à Constituição brasileira de 1988. São Paulo: Saraiva, 1997. 
GOMES, Joaquim B. Barbosa. Ação afirmativa e princípio da igualdade: o direito como instrumento de transformação social: a experiência dos EUA. Rio de Janeiro: Renovar, 2001.

- A recepção do instituto da ação afirmativa pelo direito constitucional brasileiro. Revista de Informação Legislativa, Brasília, ano 38, n. 151, p. 129-252, jul./set. 2001. Disponível em: $<$ http://www2.senado.leg.br/bdsf/item/id/705>. Acessado em: 07 abr. 2016.

GOUVEIA, Jorge Barcelar. Os direitos fundamentais atípicos. Lisboa: Aequitas Editorial Notícias, 1995.

JERUSALINSKY, Alfredo. Psicanálise e Desenvolvimento Infantil: um enfoque transdisciplinar. Porto Alegre: Artes e Ofícios, 2010.

KREL, Andreas J. Realização dos direitos fundamentais sociais mediante controle judicial da prestação dos serviços públicos básicos (uma visão comparativa). Revista de Informação Legislativa, Brasília, ano 36, n. 144, 2009.

LEAL, Rogério Gesta. Direito fundamentais em Foco: nunca é o bastante. Porto Alegre: Núria Fabris, 2012.

LEIVAS, Paulo Gilberto Cogo. Teoria dos Direitos Fundamentais Sociais. Porto Alegre: Livraria do Advogado, 2006.

LELLIS, Maximino. Princípios constitucionais do ensino. São Paulo: Lexia, 2011.

LEON, Viviane Costa de; SIQUEIRA, Maity; PARENTE, Maria Alice; BOSA, Cleonice. A especificidade da compreensão metafórica em crianças com autismo. Psico, Porto Alegre, PUCRS, v. 38, n. 3, p. 269-277, set./dez. 2007.

MACEDO, Regina Maria; FERRARI, Nery. Normas constitucionais programáticas: normatividade, operatividade e efetividade. São Paulo: Revista dos Tribunais, 2001.

MALISKA, Marcos Augusto. O direito à educação e a Constituição. Porto Alegre: Sergio Antonio Fabris Editor, 2001.

MARION, Leboyer. Autismo infantil: fatos e modelos. Campinas: Papirus, 2007.

MARTINS, Ives Gandra; MENDES, Gilmar Ferreira; NASCIMENTO, Carlos Valder. (Coord.). Tratado de Direito Constitucional, v. 1. São Paulo: Saraiva, 2010.

MARQUES, Claudia Lima; MIRAGEM, Bruno. O novo direito privado e a proteção dos vulneráveis. São Paulo: Editora Revista dos Tribunais, 2012.

MIRANDA, Jorge. Manual de Direito Constitucional, v. II. 2 ed. Coimbra: Limitada, 1983.

MORAES, Alexandre de. Direitos humanos fundamentais: teoria geral: comentários aos art. 1 a 5 da Constituição da República Federativa do Brasil: doutrina e jurisprudência. 7 ed. São Paulo: Atlas, 2006.

MORAIS, Jose Luis Bolzan de. Do direito social aos interesses transindividuais: o Estado e o direito na ordem contemporânea. Porto Alegre: Livraria do Advogado, 1996. 
NETO, Eurico Bitencourt; NETTO, Luisa Cristina Pinto. Direito Administrativo $e$ direitos fundamentais: diálogos necessários. Belo Horizonte: Fórum, 2012.

NETO, Claudio Pereira de Souza. Teoria Constitucional e Democracia Deliberativa: um estudo sobre o papel do direito na garantia das condições para a cooperação na deliberação democrática. Rio de Janeiro: Renovar, 2006.

OLIVEIRA, Valtênio Paes de. LDBEN Comentada: interpretação da Lei de Diretrizes e Bases da Educação Nacional e do Plano Nacional de Educação. Porto Alegre: Redes, 2009.

PALOMBINI, Analice de Lima et al. Acompanhamento Terapêutico na Rede Pública: A clínica em movimento. Porto Alegre: Editora UFRGS, 2004.

PAULA, Felipe de. A (de)limitação dos direitos fundamentais. Porto Alegre: Livraria do Advogado, 2010.

PIOVESAN, Flávia. Direitos humanos, globalização econômica e integração regional: desafios do direito constitucional internacional. São Paulo: Max Limonad, 2002.

; IKAWA, Daniela (Coord.). Direitos Humanos: fundamento, proteção e implementação: perspectivas e desafios contemporâneos. Curitiba: Juruá, 2008.

PEDERIVA, João Henrique. Orçamento público e relações entre os poderes. In: MESSENBERG, Débora et al. (Org.). Estudos legislativos: 20 anos da Constituição Brasileira. Brasília, 2010.

PORTO, Pedro Rui da Fontoura. Direitos Fundamentais Sociais: considerações acerca da legitimidade política a processual do Ministério Público e do sistema de justiça para a sua tutela. Porto Alegre: Livaria do Advogado, 2006.

QUEIROZ, Maria do Socorro Azevedo de. Judicialização dos direitos sociais prestacionais: a efetividade pela interdependência dos Direitos Fundamentais na Constituição Brasileira. Curitiba: Juruá, 2011.

REIS, Mauricio Martins. A decisão de inconstitucionalidade: módulo crítico para um tratamento autônomo e homogêneo. In: JOBIM, Marco Félix; FAYET, Paulo; JOBIM, Geraldo (Org.). Controvérsias Constitucionais Atuais. Porto Alegre: Livraria do Advogado, 2014.

ROBLES, Gregorio. Os direitos fundamentais e a ética na sociedade atual. Barueri: Manole, 2005.

ROCHA, Fernando Luiz Ximenes; MORAES, Filomeno (Coord.). Direito Constitucional Contemporâneo. Belo Horizonte: Del Rey, 2005.

SAAVEDRA, Giovani Agostini. Jurisdição e democracia: uma análise a partir das teorias de Jürgen Habermas, Robert Alexy, Ronald Dworkin e Niklas Luhmann. Porto Alegre: Livraria do Advogado, 2006.

SANTIN, Janaína Rigo; MORAIS, Jose Luis Bolzan de. Constituição e direitos humanos. Ou: só é possível dignidade na Constituição? In: MELGARÉ, Plínio; FILHO, Agassiz Almeida (Org.). Dignidade da pessoa humana: fundamentos e critérios interpretativos. São Paulo: Malheiros, 2010. 
SARLET, Ingo Wolfgang. A eficácia dos direitos fundamentais. 7. ed. Porto Alegre: Livraria do Advogado, 2007.

As dimensões da dignidade da pessoa humana: construindo uma compreensão jurídico constitucional necessária e possível. In: SARLET, Info Wolfgang. Dignidade da Pessoa Humana e Direitos Fundamentais na Constituição Federal de 1988. Porto Alegre: Livraria do Advogado, 2004.

. Linhas Mestras da Interpretação constitucional. In: SARLET, Ingo Wolfgang; MARINONI, Luiz Guilherme; MITIDIERO, Daniel. Curso de Direito Constitucional. 2 ed. São Paulo: Revista dos Tribunais, 2013.

(Org.). Constituição, Direitos Fundamentais e Direito Privado. Porto Alegre: Livraria do advogado, 2003.

; TIMM, Luciano Benetti (Org.). Direitos Fundamentais: orçamento e "reserva do possível". 2. ed. Porto Alegre: Livraria do Advogado, 2010.

SARMENTO, Daniel. Direitos Fundamentais e Relações Privadas. Rio de Janeiro: Lumen Juris, 2008.

SCHÄFER, Jairo. Classificação dos direitos fundamentais: do sistema geracional ao sistema unitário: uma proposta de compreensão. 2. ed. Porto Alegre: Livraria do Advogado, 2013.

STRECK, Lenio Luiz. Hermenêutica jurídica e $(m)$ crise: uma exploração hermenêutica da construção do direito. 3. ed. Porto Alegre: Livraria do Advogado, 2001.

TEPEDINO, Gustavo. Temas De Direito Civil. Rio De Janeiro: Renovar, 2001

TORRES, Marcelo Douglas de Figueiredo. Estado, democracia e administração pública no Brasil. Rio de Janeiro: Editora FGV, 2004.

TUSTIN, Frances. Barreiras autistas em pacientes neuróticos. Porto Alegre: Artes Médicas, 1990.

Recebido em: 30/11/2016

Aceito em: 26/12/2016 
Análise das ações afirmativas relativas à educação inclusiva no ensino do autista: a necessidade de monitor em sala de aula

Revista da Faculdade de Direito da UFRGS, Porto Alegre, n. 35, p. 99-115, dez. 2016.

ISSN: 0104-6594 Site http://seer.ufrgs.br/revfacdir

Faculdade de Direito da UFRGS - Rua Riachuelo, 1317 - Centro - Porto Alegre - RS - Brasil 